\title{
Changes in Hemagglutinin and Neuraminidase Genes of pH1N1 Influenza Virus Strains Collected from a North Indian Tertiary Care Hospital during 2015
}

\author{
Amita Jain Shantanu Prakash Bhawana Jain \\ Virology Division, Department of Microbiology, King George's Medical University, Lucknow, India
}

\section{Keywords}

Influenza virus · Epidemic · Haemagglutinin ·

Neuraminidase $\cdot$ Mutation

\begin{abstract}
Objective: The study was conducted to analyze changes in $\mathrm{HA}$ and NA genes of pandemic $\mathrm{pH} 1 \mathrm{~N} 1$ strains, collected from North Indian tertiary care hospital during 2015 and studied the nucleotide change since 2009. Differences in clinical features of cases positive and negative for influenza viruses were also studied. Methods: All samples referred for H1N1 testing, were tested for influenza viruses. Randomly selected 25 strains of $\mathrm{pH} 1 \mathrm{~N} 1$ were studied for nucleotide sequences of HA \& NA gene. The nucleotide changes occurring since 2009 were studied by mutational and phylogenetic analysis. Clinical details of cases were recorded and analysed. Results: A total of 3319 cases of acute respiratory infections (ILI/SARI) were tested for influenza viruses during Jan to April 2015, of which 815 cases tested positive for $\mathrm{pH} 1 \mathrm{~N} 1$. Nucleotide variation of 2015 strains, from influenza A/California/07/2009 strain at $\mathrm{HA} 1$ and $\mathrm{NA} 1$ gene was $1.9 \%$ and $3.8 \%$ respectively. Both HA1 and NA1 coding sequence showed eight mutations. Four of HA1(K180Q, S202T, S220T, and A273T) and NA1 (N200S, V2411, N248D, and N270K) mutations were observed in all pH1N1 study strains. Conclusions: Strains of pH1N1
\end{abstract}

isolated during year 2015 diverged from previously circulating strains. Their association with severity of illness needs to be further studied.

(c) 2018 S. Karger AG, Basel

\section{Background}

A novel influenza A (pH1N1) strain emerged in 2009, which caused a major pandemic worldwide. At the beginning of the year 2015, the $\mathrm{pH} 1 \mathrm{~N} 1$ flu epidemic re-emerged in India. Around 33,000 number of cases with death of more than 2,000 people was reported by mid-February 2015 [1]. States of Rajasthan, Gujarat, Telangana, Delhi, and Jammu and Kashmir were worst affected [2]; however, an unusual increase in number of cases was seen in 2015 across the whole of India including the state of Uttar Pradesh.

The changes in influenza virus antigens especially hemagglutinin (HA) and neuraminidase (NA) due to antigenic shifts/drifts are largely responsible for change in viral characters including pathogenicity [3]. It is important to characterize influenza strains on the basis of these antigens especially the active sites of HA1 domain of HA gene and NA domain of NA gene to determine the genetic changes on a regular basis. Hence, we studied the 
changes in $\mathrm{HA} 1$ and NA genes of $\mathrm{pH} 1 \mathrm{~N} 1$ strains isolated during January to April, 2015, that is the flu epidemic period in India, and analyzed the changes that had occurred in HA1 and NA genes of pH1N1 strains since 2009. The clinical features of influenza positive and negative patients were analyzed to study the significant association of clinical features with influenza positivity.

\section{Material and Methods}

From January 25 to April 26, 2015, patients presenting with clinical diagnosis of influenza-like illness (ILI) and/or severe acute respiratory illness (SARI), referred to Virus diagnostic and research laboratory, Department of Microbiology, King George's Medical University, Lucknow, Uttar Pradesh, India, were tested for influenza viruses ( $\mathrm{pH} 1 \mathrm{~N} 1$, influenza A H3N2, and influenza B). The center for disease control (CDC) guidelines for ILI and SARI case definitions were followed [4]. Nasal and throat swabs/nasopharyngeal aspirates were collected from each patient and processed for molecular diagnosis of human influenza viruses by realtime reverse transcriptase polymerase chain reaction (PCR) [5]. Informed consent was obtained from all the patients/their guardians (in case of children). Institutional ethical clearance was taken.

Clinical details of all the cases were collected on a predesigned questionnaire and compared for influenza $\mathrm{pH} 1 \mathrm{~N} 1$ positive and negative patients. Significant association was determined by chisquare test. All statistical analyses were done using SPSS 16.0 version software.

A total of 25 randomly selected $\mathrm{pH} 1 \mathrm{~N} 1$ strains were characterized for HA1 and NA genes. The $447 \mathrm{bp}$ segment of HA1 gene (nucleotide position 434-905) and 1,159 bp segment of NA gene (nucleotide position 10-1,159) were amplified by one-step RT PCR assay as described earlier [6, 7]. Amplified products were confirmed by running on $2 \%$ agarose gel-electrophoresis and visualized on a UV trans-illuminator after staining with ethidium bromide solution. The PCR product seen as a single band was directly used for further purification process by Exo-Sap treatment (by Exonuclease I, $1 \mathrm{U} / \mu \mathrm{L}$ and Shrimp Alkaline Phosphatase, $20 \mathrm{U} / \mu \mathrm{L}$; FastApTM, Fermentas) and ethanol precipitation. Purified products were sequenced using BigDye Terminator Cycle-Sequencing Kit (Applied Biosystems, Foster City, CA, USA) on ABI 3130 genetic Analyzer (Applied Biosystems, Foster City, CA, USA).

Nucleotide sequences were edited and subjected to BLAST search for similar sequences in GenBank Database. To determine genetic changes in study strain, the nucleotide and amino acid sequences were compared to influenza A/California/07/2009 strain (2010 vaccine strain). Nucleotide and amino acid sequences were retrieved from the Influenza Research Database (www. fludb.org).

The amino acid sequences of study strains were deduced from nucleotide sequences in EXPASY translate tool. The percent nucleotide and amino acid identity was determined as pairwise $\mathrm{p}$ distances by comparing sequences in MEGA 5.05 software.

To study the changes from previous strains and other global data base, nucleotide and coding sequences of 2015 study strains were compared with published cognate sequences of cor- responding genes from our previous published data [8]. Pairwise $\mathrm{p}$ distances analysis of their HAl and NA genes was carried out to decipher the divergence from previously circulating strains.

A phylogenetic analysis of 2012, 2013, and 2015 influenza pH1N1 strains was done. Phylogenetic tree was constructed using the maximum likelihood approach in PhyML program [9]. The HKY85+I+G4 nucleotide substitution model was utilized in this analysis and $\mathrm{SH}$-like branch support was employed. The statistical inference of phylogenetic tree was measured on 500 bootstrap replicates.

\section{Results}

A total of 3,319 cases of acute respiratory infections (ILI/SARI) were referred to the study site during January 25-April 30, 2015, and tested for influenza viruses, of which 815 cases tested positive for influenza $\mathrm{A}(\mathrm{pH} 1 \mathrm{~N} 1)$, 6 for influenza A (H3N2), and 17 for influenza B. Complete clinical details were available in only 3,292 cases; hence 28 subjects were deleted from analysis. Patient's age, clinical symptoms (cough, coryza, chills, breathlessness, vomiting, headache, body ache), and duration of fever were analyzed as independent variables. Details are given in the Table 1. Cough, duration of illness $<3$ days, and age $>45$ years and $<2$ years, demonstrated a positive association with influenza positivity.

\section{Comparative and Mutational Analysis of pH1N1}

Strain of Year 2015, 2012, and 2013

Nucleotide variation of 2,015 strains from reference influenza A/California/07/2009 strain at the HA1 and NA gene was 1.9 and $3.8 \%$, respectively, while divergence at protein level was 4.2 and $5.5 \%$, respectively. Nucleotide divergence of 2,012 strains from reference strain at the HA 1 and NA gene both was $1.3 \%$ while divergence at protein level for HA1 and NA protein was 3.0 and $1.7 \%$, respectively. Nucleotide divergence of 2,013 strains from reference strain at the HA1 and NA gene was 1.7 and $1.6 \%$, respectively, while divergence at protein level for HA1 and NA protein was 3.7 and $2.5 \%$, respectively (Table 2).

Comparison of the HA1 coding sequence of 2015 pH1N1 strains with prototype strain showed 8 mutations. Four mutations (K180Q, S202T, S220T, and A273T) were observed in all pH1N1 2015 strains (Table 3). Figure 1 shows the phylogenetic analysis of HA1 gene; $\mathrm{pH} 1 \mathrm{~N} 1$ strains isolated during 2015 years diverged from clade 7 genotype of 2,009 pandemic H1N1 strains. Three of the mutations seen in 2,015 strains (D185N, D213N, and H290Q) were not reported before. 
Table 1. Comparative analysis of different parameters (age group analysis, clinical presentations, and durations of fever) in patients positive for influenza $\mathrm{A}(\mathrm{H} 1 \mathrm{~N} 1)$ pdm09 virus and patients negative of respiratory viruses

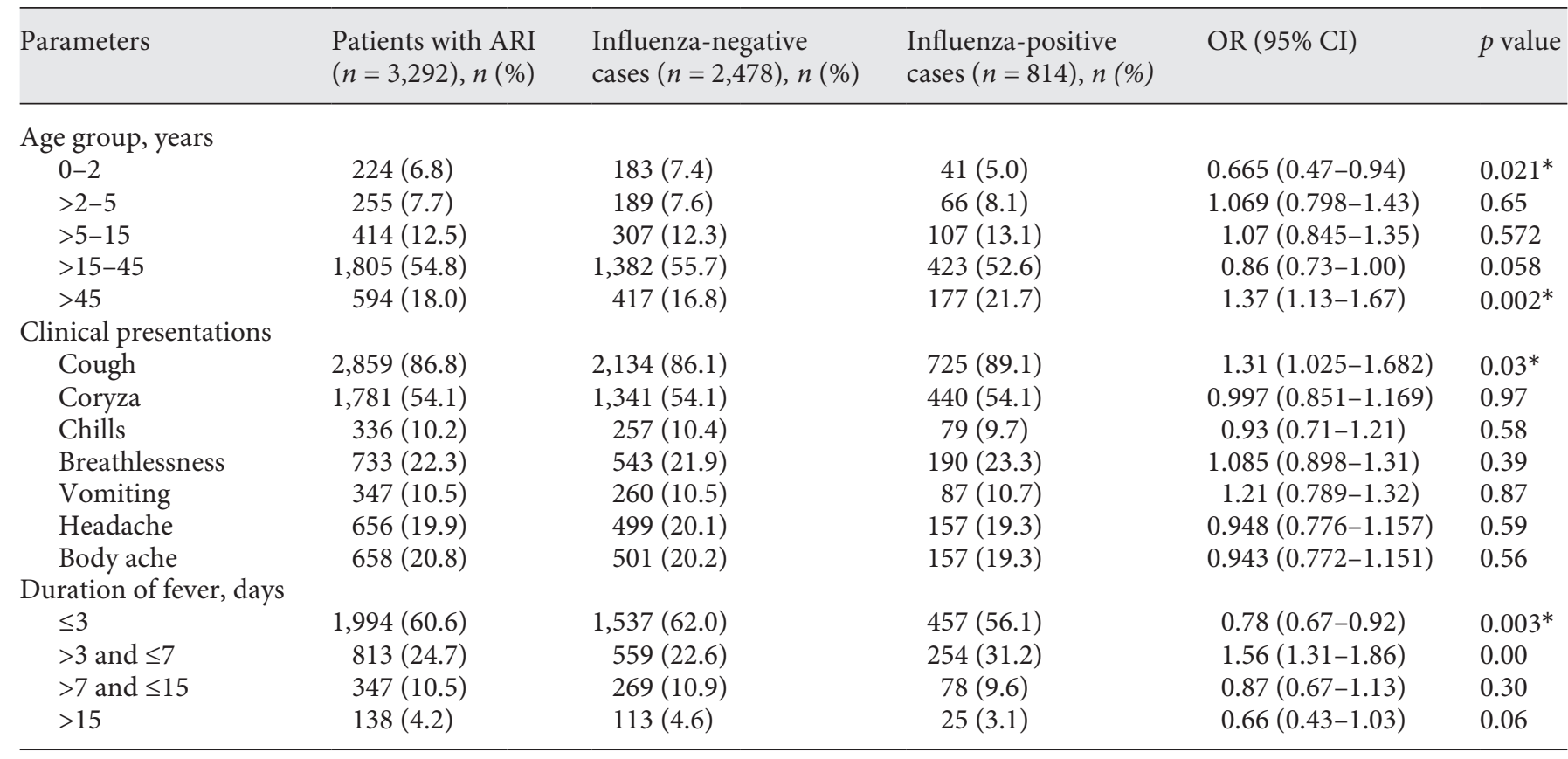

$* p \leq 0.05$ considered as significant.

Table 2. Divergence of HAl and N1 nucleotide and/coding sequences of study strains isolated during 2012, 2013, and 2015 with reference strain (A/California/07/2009)

\begin{tabular}{llll}
\hline & 2012 & 2013 & 2015 \\
\hline HA1 gene & & & \\
$\quad$ Nucleotide divergence, \% & 1.3 & 1.7 & 1.9 \\
$\quad$ Amino acid divergence, \% & 3.0 & 3.7 & 4.2 \\
N1 gene & & & \\
$\quad$ Nucleotide divergence, \% & 1.3 & 1.6 & 3.8 \\
$\quad$ Amino acid divergence, \% & 1.7 & 2.5 & 5.5 \\
\hline
\end{tabular}

Eight mutations were identified in NA amino acid sequences of 2,015 pH1N1 strains when compared to prototype strains (Table 4). All strains showed 4 mutations at different amino acid positions, that is, N200S, V241I, $\mathrm{N} 248 \mathrm{D}$, and $\mathrm{N} 270 \mathrm{~K}$. In the phylogenetic analysis of NA gene, all 2015 pH1N1 strains got separated from 2,009 vaccine strains and made a single cluster in phylogenetic tree (Fig. 2).

The nucleotide sequences of pandemic HAl gene and NA genes derived in the study were deposited into the GenBank database under accession numbers KR140136,
KR140138 - KR140141, KR140143, KR140144, KR140147 - KR140150, KT873519 - KT873527, KT873529 KT873532, and KT873494 - KT873518.

\section{Discussion}

The present study demonstrated that $\mathrm{pH} 1 \mathrm{~N} 1$ study strains showed more changes in active sites of NA gene as compared to HA gene. Molecular analysis at gene level (especially HA1 and NA genes) identified few mutational changes which were different from the previously circulating strains of $\mathrm{pH} 1 \mathrm{~N} 1$ virus as described earlier $[6,10]$. Mutational changes in the active site of HA1 protein showed 5 mutations, similar to previously circulating $\mathrm{pH} 1 \mathrm{~N} 1$ strains of Indian region along with 3 new mutations in 2015 strains at different positions (D185N, D213N, and H290Q) [11]. These mutations are also not reported in any other regions of India. There was higher nucleotide and amino acid variation in NA gene, in reference to HA gene when compared to reference influenza A/California/07/2009 strain. However, when the Lucknow strains from years 2012 and 2013 were compared, the nucleotide divergence rate was higher in HA gene, as reported in ear- 
Table 3. Amino acid changes at various positions in HA1 coding sequences (from position 160aa to 300aa) of Lucknow strains

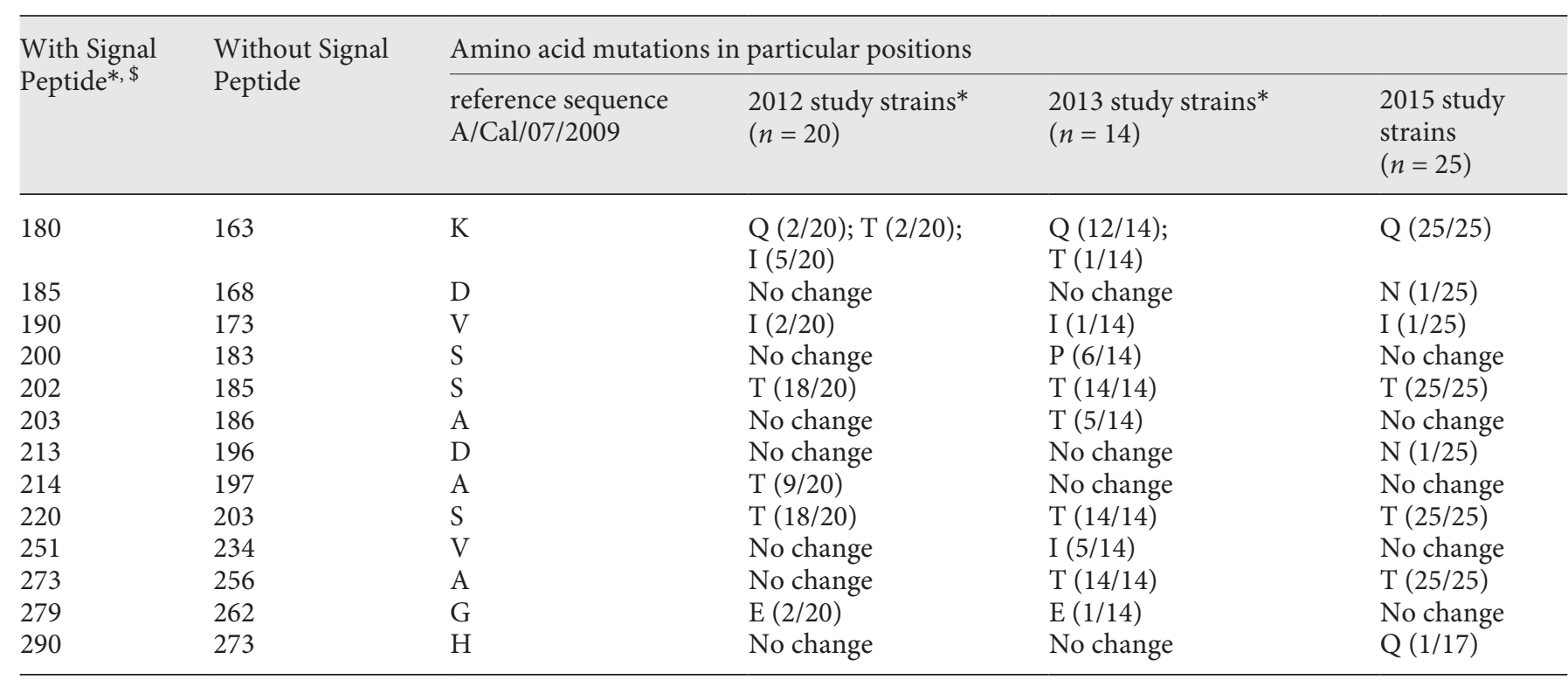

* Dangi et al. [6], 2014.

\$ Initial 16-20 base pair cleaved, Suzuki et al. [11], 2002.

Table 4. Amino acid changes at various positions in N1 coding sequences (from position 180aa to 300aa) of Lucknow strains

\begin{tabular}{|c|c|c|c|c|}
\hline $\begin{array}{l}\text { Amino acid } \\
\text { positions in } \\
\text { N1 protein }\end{array}$ & \multicolumn{4}{|c|}{ Amino acid mutations in particular positions } \\
\hline 200 & $\mathrm{~N}$ & $\mathrm{D}(12 / 37) ; \mathrm{S}(10 / 37)$ & $S(21 / 33)$ & $S(25 / 25)$ \\
\hline 232 & A & $\mathrm{T}(3 / 37)$ & $\mathrm{T}(6 / 33)$ & No change \\
\hline 234 & $\mathrm{~V}$ & $\mathrm{I}(6 / 37)$ & No change & No change \\
\hline 257 & $\mathrm{R}$ & No change & $K(6 / 33)$ & No change \\
\hline 260 & $\mathrm{~K}$ & No change & $\mathrm{E}(3 / 33)$ & No change \\
\hline 264 & $\mathrm{~V}$ & No change & No change & $\mathrm{I}(21 / 25)^{\circ}$ \\
\hline 270 & $\mathrm{~N}$ & No change & No change & $\mathrm{K}(25 / 25)$ \\
\hline 273 & $\mathrm{~N}$ & No change & $\mathrm{K}(6 / 33)$ & No change \\
\hline 285 & S & No change & No change & $\mathrm{Y}(1 / 25)$ \\
\hline
\end{tabular}

* Dangi et al. [6], 2014.

Fig. 1. Phylogenetic tree of the $\mathrm{pH} 1 \mathrm{~N} 1$ hemagglutinin (HA1) sequences: Phylogenetic tree with HAlgene from influenza A (pH1N1) viruses circulating in Northern India during year 2015, rooted by HA1 reference sequences of influenza A/
California/4/2009 (shown in circle). Representative strains of years 2012 and 2013 from Northern India are shown for comparison. The reliability of branches was evaluated on 500 bootstrap replicates.

(For figure 1 see next page.) 


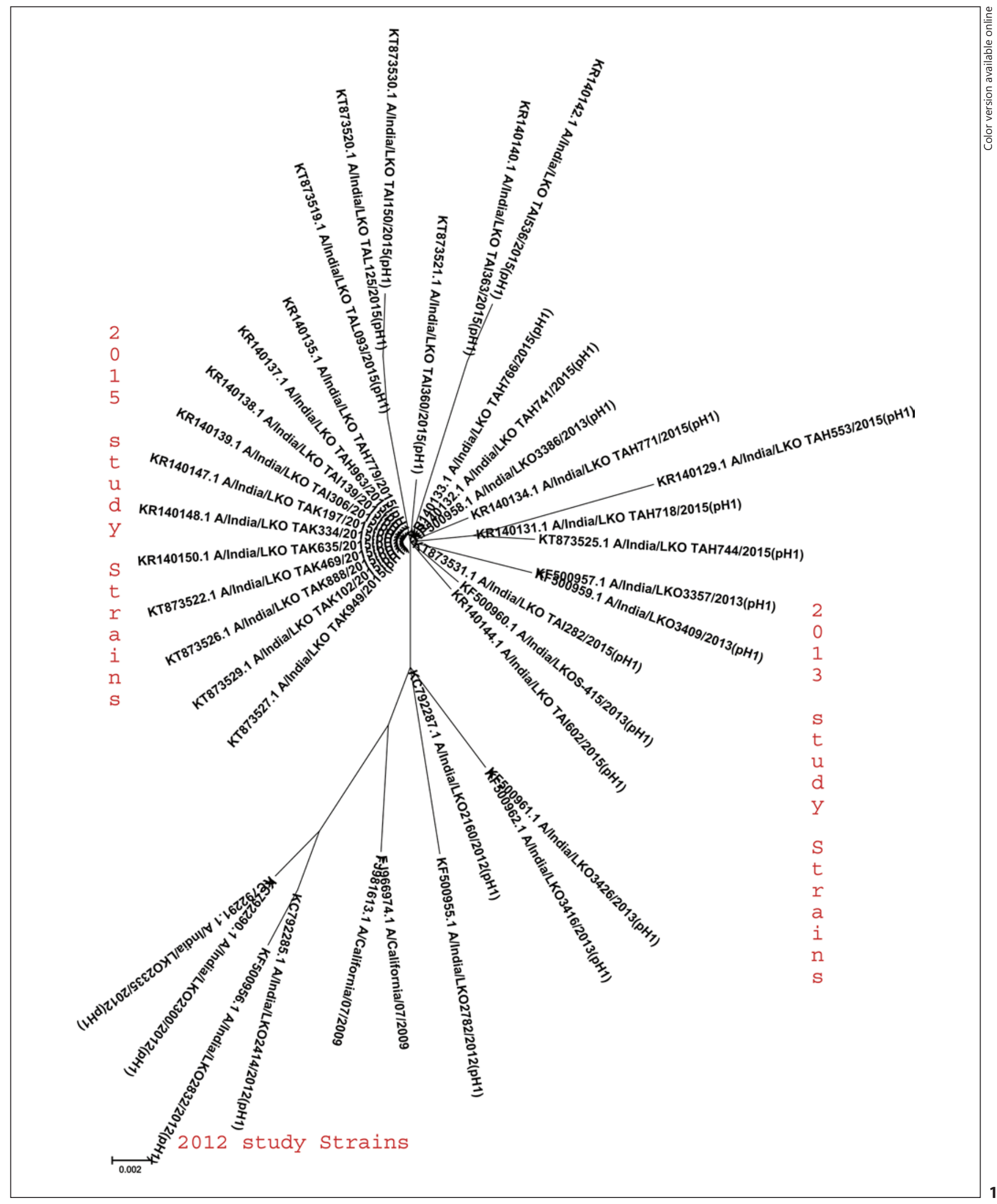

Changes in HA and NA Genes of pH1N1

Intervirology 2017;60:263-270 


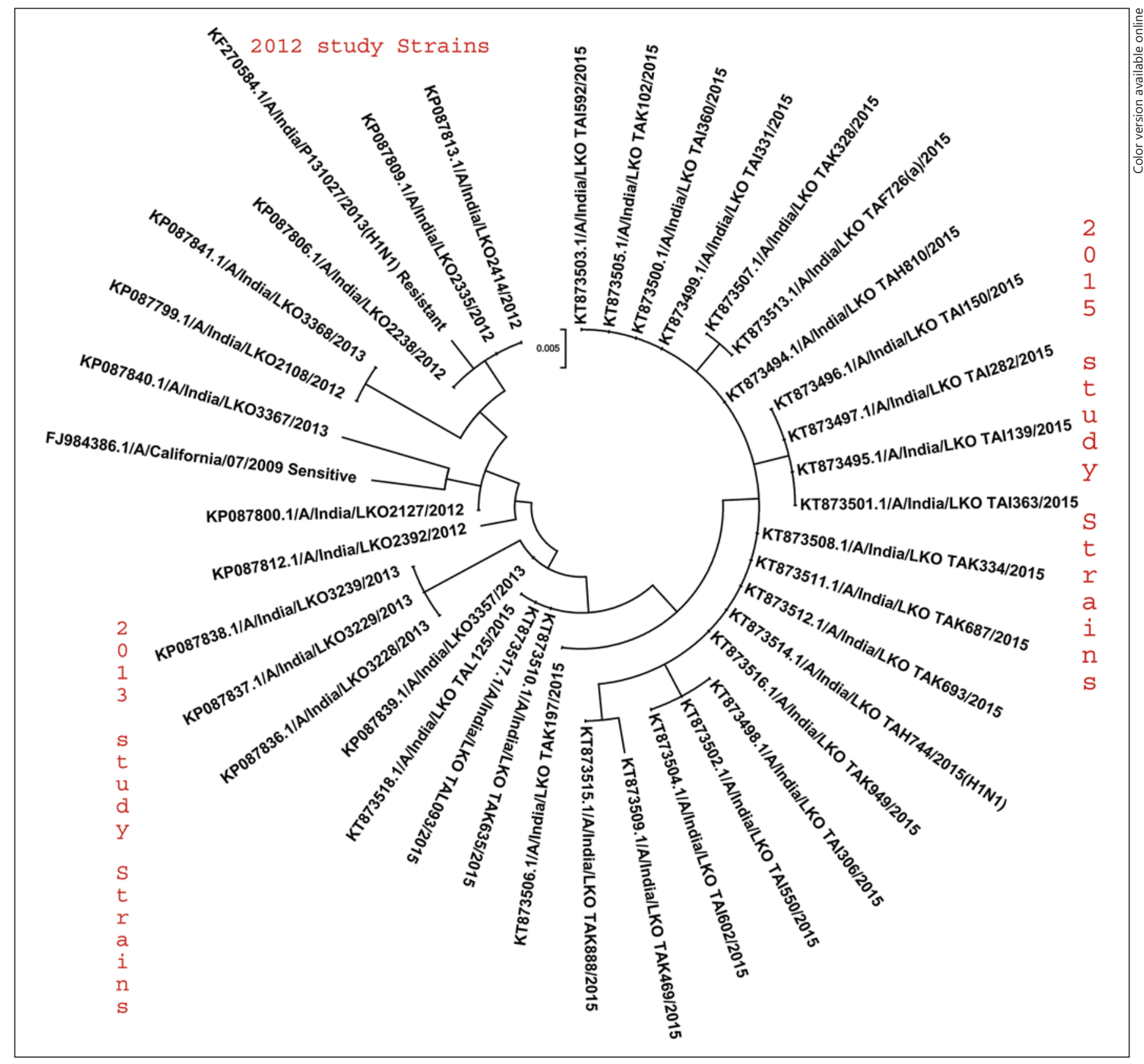

Fig. 2. Phylogenetic tree of the pH1N1 neuraminidase (NA) sequences: Phylogenetic tree with NA gene from influenza A (pH1N1) viruses circulating in Northern India during year 2015, rooted by NA sequences from A/California/07/2009 and A/India.

lier studies. From an evolutionary perspective, the HA gene has been accumulating mutations more rapidly than the NA and NP genes; however, the rate of amino acid substitution in HA gene is lower. The cumulative amino acid changes in HA gene can be explained as lack of proofreading of viral RNA polymerase activity $[12,13]$.
P131027/2013 (reference strains are shown in circle). Representative strains of years 2012 and 2013 from Northern India are shown for comparison. The reliability of branches was evaluated on 500 bootstrap replicates.
For a new epidemic to occur, the HA protein of influenza virus has to mutate enough to become antigenically distinct to a significant percentage $[14,15]$. As shown by the earlier studies, the probability of a new epidemic will increase when the amino acid substitutions in the HA protein exceeds $10[16,17]$ or the num- 
ber of amino acid substitutions in the epitope regions exceeds 4 [18]. One study done at Massachusetts Institute of Technology, USA, documented unidentified mutations (K166Q, D225, and T200A mutations in HA1 gene) in 2015 Indian outbreak strains and interpreted that these new acquired mutations are responsible for more virulence of Indian $\mathrm{pH} 1 \mathrm{~N} 1$ strain seen in year 2015 [19]. We did not find any of these mutations in our strains. According to Indian health officials, the pH1N1 strain has not changed much from the first strain that emerged in 2009 [20]. The phylogenetic analysis based on partial HA1 gene sequences of study strains revealed the presence of 2 mutations (S220T and S202T) in HA1 gene of all study strains which are specific to clade 7 genotype of pH1N1 [6, 10, 21-23].

Results of present study show that NA gene showed more divergence in coding sequences as compared to HA gene. In study strains, 3 mutations (N200S, V241I, and N248D) were similar to those reported in 2012 and 2013 pH1N1 strains reported by our group; while, 5 new mutations in NA protein were identified (V264I, N270K, S285Y, E287K, and I314M) causing diversion of 2015 pH1N1 strains from reference strains as observed in the phylogenetic tree (Fig. 2). There are 8 functional amino acids sites (R118, D151, R152, R224, E276, R292, R371, and Y406 - N2 numbering throughout) and 11 structural amino acid site (E119, R156, W178, S179, D/N198, I222, E227, H274, E277, D293, and E425) that are conserved in almost all IAV subtypes and serve as target of drug zanamivir (Relenza) and oseltamivir (Tamiflu). There was no mutation seen in the mentioned active sites leading to minimal possibility of resistance to the drugs [24]. However, presence of new mutations in the coding region of HA1 and NA gene may have possibly contributed to the severity of outbreak.

At the beginning of 2009 pandemic, young adults were found to be more affected by $\mathrm{pH} 1 \mathrm{~N} 1$ infection and mortality was high in elders (age over 60 years) and children $[25,26]$. Similar observation was depicted during 2015 flu outbreak where higher influenza positivity was seen in patients belonging to $>45$ years of age group ( $p$ $\leq 0.05$ ) but significantly low positivity was observed in children $<2$ years of age. Cough was significantly associated with affected groups; however, cough, fever, and sore throat are included as enrolment criteria as defined by CDC case definition. Higher influenza positivity was seen in patients presenting with fever $<3$ days duration.

India is a vast country with diverse climate and demonstrates 2 seasonal activities of influenza, one during monsoon months which is observed in most part of the country with tropical climate and other in winter period which is observed in the temperate region of northern part of the country [27-29]. Previous studies on influenza seasonality in most parts of India and other parts of world demonstrated peak influenza activity in monsoon season and some showed positive association with humidity and rainfall [30, 31]. In contrast to this, 2015 flu outbreak demonstrated a major peak in $\mathrm{pH} 1 \mathrm{~N} 1$ outbreak in the winter months of 2015. The data collected in the present study cannot provide any possible explanation for this phenomena; however, this remains a query for inquisitive minds. No unusual increase in cases was seen in January to April 2016.

\section{Conclusion}

Strains of pH1N1 isolated during year the 2015 diverged from previously circulating strains and new mutations were seen. Their association with severity of illness need to be studied.

\section{Acknowledgment}

The authors would like to acknowledge the Indian Council of Medical Research, New Delhi, India, for financial support (5/8/7/14/2009-ECD-1). We are grateful to the staff of Virology Diagnostic Laboratory (VDL) for their contribution in diagnosis and investigation of outbreak cases during 2015.

\section{Disclosure Statement}

The authors have no conflicts of interest to disclose.

\section{References}

1 Ministry of Health and Family WelfareGovernment of India, 2015: Laboratory Confirmed Cases and Deaths Caused by Pandemic Influenza A H1N1: State/UTwise. http://www.mohfw.nic.in/showfile. php?lid = 2614 (Last accessed March 8, 2015).

2 Bloomberg Business News 2015 by Adi Narayan. India struggles to contain H1N1 Outbreak as Death toll hits 700. Feburary 20, 2015. http://www.bloomberg. com/news/articles/2015-02-20/india-struggles-to-contain-h1n1-outbreak-as-deathtoll-hits-700

3 Mair CM, Ludwig K, Herrmann A, Sieben C: Receptor binding and $\mathrm{pH}$ stability - how influenza A virus hemagglutinin affects hostspecific virus infection. Biochim Biophys Acta 2014;1838:1153-1168. 
4 Centers for Disease Control and Prevention (CDC): Interim Guidance on Case Definitions to be Used for Investigations of Novel Influenza A (H1N1) Cases, 2009. http://www. cdc.gov/h1n1flu/casedef.htm (accessed October 13, 2011).

5 WHO, CDC Protocol of Real-Time RTPCR for Swine Influenza A (H1N1), 2009. http:// www.who.int/csr/resources/publications/ swineflu/CDCRealtimeRTPCR_Swine H1Assay-2009_20090430.pdf (accessed March 15, 2011).

6 Dangi T, Jain B, Singh AK, Singh JV, Kumar R, Dwivedi M, Verma AK, Chadha MS, Jain A: Molecular characterization of circulating pandemic strains of influenza A virus during 2012 to 2013 in Lucknow (India). J Med Virol 2014;86:13-18.

7 Jain A, Dangi T, Jain B, Singh AK, Singh JV, Kumar R: Genetic changes in influenza $\mathrm{A}(\mathrm{H} 3 \mathrm{~N} 2)$ viruses circulating during 2011 to 2013 in Northern India (Lucknow). J Med Virol 2014;9999:1-8.

8 Dangi T, Jain B, Singh AK, Mohan M, Dwivedi M, Singh JV, Kumar R, Singh KP, Chaddha MS, Mishra AC, Jain A: Influenza virus genotypes circulating in and around Lucknow, Uttar Pradesh, India, during post pandemic period, August 2010 - September 2012. Indian J Med Res 2014;139:418-426.

9 Guindon S, Gascuel O: A simple, fast, and accurate algorithm to estimate large phylogenies by maximum likelihood. Syst Biol 2003; 52:696-704.

10 Mir AM, Lal RB, Sullender W, Singh Y, Garten R, Krishnan A, Broor S: Genetic diversity of HA1 domain of hemagglutinin gene of pandemic influenza H1N1pdm09 viruses in New Delhi, India. J Med Virol 2012;84:386-393.

11 Suzuki Y, Nei M: Origin and evolution of influenza virus hemagglutinin genes. Mol Biol Evol 2002;19:501-509.

12 Nelson MI, Holmes EC: The evolution of epidemic influenza. Nat Rev Genet 2007;8:196205
13 Rabadan R, Robins H: Evolution of the influenza a virus: some new advances. Evol Bioinform 2007;3:299-307.

14 Wolf YI, Nikolskaya A, Cherry JL, Viboud C, Koonin E, et al: Projection of seasonal influenza severity from sequence and serological data. PLoS Curr 2010;2:RRN1200.

15 Wu A, Peng Y, Du X, Shu Y, Jiang T: Correlation of influenza virus excess mortality with antigenic variation: application to rapid estimation of influenza mortality burden. PLoS Comput Biol 2010;6:e1000882.

16 Park AW, Daly JM, Lewis NS, Smith DJ, Wood JL, et al: Quantifying the impact of immune escape on transmission dynamics of influenza. Science 2009;326:726-728.

17 Smith CB, Cox NJ, Subbarao K, Taber LH, Glezen WP: Molecular epidemiology of influenza $\mathrm{A}(\mathrm{H} 3 \mathrm{~N} 2)$ virus reinfections. J Infect Dis 2002;185:980-985.

18 Wilson IA, Cox NJ: Structural basis of immune recognition of influenza virus hemagglutinin. Annu Rev Immunol 1990;8:737787.

19 Tharakaraman K, Sasisekharan R: Influenza Surveillance: 2014-2015 H1N1 "Swine"-derived Influenza viruses from India. Cell Host Microbe 2015;17:279-282.

20 Herriman R: March 12, 2015. India H1N1 MIT Study: Health Ministry Refutes Mutation Findings. http://outbreaknewstoday. com/india-hln1-mit-study-health-ministryrefutes-mutation-findings-99590/.

21 Nelson M, Spiro D, Wentworth D, Beck E, Fan J, Ghedin E, Halpin R, Bera J, Hine E, Proudfoot K, et al: The early diversification of influenza A/H1N1pdm. PLoS Curr 2009; 1:RRN1126.

22 Mullick J, Cherian SS, Potdar VA, Chadha MS, Mishra AC: Evolutionary dynamics of the influenza A pandemic (H1N1) 2009 virus with emphasis on Indian isolates: evidence for adaptive evolution in the HA gene. Infect Genet Evol 2011;11:997-1005.
23 Morlighem JE, Aoki S, Kishima M, Hanami M, Ogawa C, Jalloh A, Takahashi Y, Kawai Y, Saga S, Hayashi E, Ban T, et al: Mutation analysis of 2009 pandemic influenza $\mathrm{A}(\mathrm{H} 1 \mathrm{~N} 1)$ viruses collected in Japan during the peak phase of the pandemic. PLoS One 2011;6:e18956.

24 Hussain M, Galvin HD, Haw TY, Nutsford AN, Husain M: Drug resistance in influenza A virus: The epidemiology and management. Infect Drug Resist 2017;10: 121-134.

25 Das RR, Sami A, Lodha R, Jain R, Broor S, Kaushik S, Singh BB, Ahmed M, Seth R, Kabra SK: Clinical profile and outcome of swine flu in Indian children. Indian Pediatr 2010;48: 373-378.

26 Greer AL, Tuite A, Fisman DN: Age, influenza pandemics and disease dynamics. Epidemiol Infect 2010;138:1542-1549.

27 Koul P, Khan U, Bhat K, Saha S, Broor S, Lal $\mathrm{R}$, Chadha M: Recrudescent wave of A/ H1N1pdm09 influenza viruses in Winter 2012-2013 in Kashmir, India. PLoS Curr 2013;5:pii.

28 Koul PA, Broor S, Saha S, Barnes J, Smith C, Shaw M, et al: Differences in influenza seasonality by latitude, northern India. Emerg Infect Dis 2014;20:1723-1726.

29 Clem A, Galwankar S: Seasonal influenza: waiting for the next pandemic. J Glob Infect Dis 2009;1:51-56.

30 Azziz Baumgartner E, Dao CN, Nasreen S, Bhuiyan MU, Mah-E-Muneer S, Al Mamun A, Sharker MA, Zaman RU, Cheng PY, Klimov AI, Widdowson MA, et al: Seasonality, timing, and climate drivers of influenza activity worldwide. J Infect Dis 2012;206:838846

31 Zaraket H, Dapat C, Ghanem S, Ali Z, Lteif M, Kondo $\mathrm{H}$, et al: Characterization of human influenza viruses in Lebanon during 2010-2011 and 2011-2012 post-pandemic seasons. Intervirology 2014;57:344-352. 